\title{
The Intraflagellar Transport Protein IFT27 promotes BBSome exit from cilia through the GTPase ARL6/BBS3
}

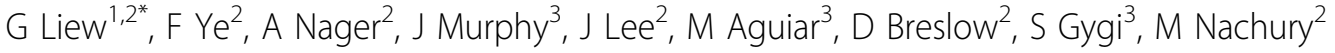 \\ From Cilia 2014 - Second International Conference \\ Paris, France. 18-21 November 2014
}

\section{Objective}

To dissect the regulation of ciliary trafficking by small GTPases.

\section{Methods}

Proteomics, Enzymology, Immunocytochemistry, Livecell photokinetics.

\section{Results}

Upon disengagement from the IFT-B complex, the IFT27/RabL4 subunit directly and specifically recognizes nucleotide-empty ARL6.

IFT27 stabilizes nucleotide-empty ARL6 against aggregation, supporting a role for IFT27 in promoting nucleotide exchange on ARL6.

Immunocytochemistry on IFT27-depleted cells reveals hyperaccumulation of ARL6 and BBSome in cilia.

Direct measurements of ciliary entry and exit rates show that IFT27 promotes BBSome exit out of cilia with no influence on entry, thus placing the site of IFT27 action within cilia.

While the BBSome is normally associated with IFT trains inside cilia, most of the BBSome is dissociated from IFT trains in IFT-depleted cells.

A putative BBSome cargo, the Hedgehog signaling intermediate GPR161, accumulates inside cilia of IFT27 and ARL6 knockout cells.

\section{Conclusions}

Our data suggest that upon disassembly of IFT/BBSome trains at the tip, the IFT27 subunit transiently detaches from the IFT complex to participate in GTP loading onto

'Department of Biochemistry, Stanford University School of Medicine, Stanford, CA, USA

Full list of author information is available at the end of the article
ARL6, which then triggers formation of a retrograde BBSome coat for trafficking of the BBSome and its associated cargoes out of cilia. In other words, the disassembly of an anterograde IFT/BBSome train produces the trigger for assembly of the future retrograde IFT/BBSome train.

\section{Authors' details \\ ${ }^{1}$ Department of Biochemistry, Stanford University School of Medicine, Stanford, CA, USA. ${ }^{2}$ Department of Molecular and Cellular Physiology, Stanford University School of Medicine, Stanford, CA, USA. ${ }^{3}$ Department of Cell Biology, Harvard Medical School, Cambridge, MA, USA.}

Published: 13 July 2015

doi:10.1186/2046-2530-4-S1-018

Cite this article as: Liew et al.: The Intraflagellar Transport Protein IFT27 promotes BBSome exit from cilia through the GTPase ARL6/BBS3. Cilia 2015 4(Suppl 1):018.
Submit your next manuscript to BioMed Central and take full advantage of:

- Convenient online submission

- Thorough peer review

- No space constraints or color figure charges

- Immediate publication on acceptance

- Inclusion in PubMed, CAS, Scopus and Google Scholar

- Research which is freely available for redistribution
() Biomed Central 